\title{
In situ vaccination by radiotherapy to improve responses to anti-
}

\section{CTLA-4 treatment.}

Claire Vanpouille-Box ${ }^{1}$, Karsten A. Pilones ${ }^{1}$, Erik Wennerberg ${ }^{1}$, Silvia C. Formenti ${ }^{2}$ and Sandra Demaria $^{1,2^{*}}$.

Departments of ${ }^{1}$ Pathology and ${ }^{2}$ Radiation Oncology, New York University School of Medicine, and NYU Cancer Institute, New York, New York 10016.

- Corresponding author: Sandra Demaria, Departments of Pathology and Radiation Oncology, New York University School of Medicine, Alexandria Center for Life Sciences, 450 E $29^{\text {th }}$ Street, New York, New York, 10016, USA. Phone: 1.212.263.7308. sandra.demaria@nyumc.org

Running title: Radiation-induced vaccination and anti-CTLA-4 treatment

Conflict of interest: The authors declare that no conflict of interest exists 


\section{$\underline{\text { Abstract }}$}

Targeting immune checkpoint receptors has emerged as an effective strategy to induce immunemediated cancer regression in the subset of patients who have significant pre-existing anti-tumor immunity. For the remainder, effective anti tumor responses may require vaccination. Radiotherapy, traditionally used to achieve local tumor control, has acquired a new role, that of a partner for immunotherapy. Ionizing radiation has pro-inflammatory effects that facilitate tumor rejection. Radiation alters the tumor to enhance the concentration of effector $\mathrm{T}$ cells via induction of chemokines, cytokines and adhesion molecules. In parallel, radiation can induce an immunogenic death of cancer cells, promoting cross-presentation of tumor-derived antigens by dendritic cells to T cells. Newly generated anti-tumor immune responses have been demonstrated post-radiation in both murine models and occasional patients, supporting the hypothesis that the irradiated tumor can become an in situ vaccine. It is in this role, that radiation can be applied to induce anti-tumor T cells in lymphocyte-poor tumors, and possibly benefit patients who would otherwise fail to respond to immune checkpoint inhibitors. This review summarizes preclinical and clinical data demonstrating that radiation acts in concert with antibodies targeting the immune checkpoint cytotoxic T-lymphocyte antigen-4 (CTLA-4), to induce therapeutically effective anti-tumor $\mathrm{T}$ cell responses in tumors otherwise non responsive to anti-CTLA-4 therapy. 


\section{$\underline{\text { Introduction }}$}

From the inception of carcinogenesis, the immune system detects and eliminates nascent tumors in a process described as cancer immunosurveillance. Stress-induced ligands and altered antigenicity render transformed cells susceptible to natural killers (NK) cells, $\gamma \delta$ and conventional $\alpha / \beta$ T cells. Tissue disruption and unscheduled cell death that occur during tumor progression to invasion generate dangers signals in the form of damage-associated molecular pattern (DAMP) molecules that alert the immune system of a potential threat, activating both innate and adaptive immunity [1]. However, occasionally elimination of cancer cells is incomplete and cancer cells that have acquired the ability to evade immune control emerge, as a result of the selective pressure of the immune system. Thus, cancers rise to clinical detection after a long and complex crosstalk with the immune system, while a dominant immune suppressive tumor micro-environment has also emerged. The latter is enriched in cells with regulatory and immunosuppressive function that secrete cytokines such as transforming growth factor- $\beta$ (TGF $\beta)$ and IL-10, which counteract immune-mediated rejection [2]. Noticeably, in some patients robust anti-tumor $\mathrm{T}$ cell responses are detectable at clinical diagnosis and their presence in the tumor specimen has been associated with a better prognosis $[3,4]$. Patients who retain such anti-tumor immunity appear to benefit the most from immunotherapy, even at advanced stages of the disease [5]. For example, responses to immune checkpoint inhibitors rely on the patient's pre-existing anti-tumor T cells $[6,7]$. Unfortunately, only a small fraction of cancer patients retains sufficient anti-tumor immune responses. Among solid tumors patients, melanoma carriers are most likely to respond to immune checkpoint inhibitors targeting CTLA-4 or programmed cell death-1 (PD-1) [8, 9], possibly because of their high mutational load [10]. 
Because responses to anti-CTLA-4 often are durable [11, 12], identifying combination treatments that can convert patients unresponsive to CTLA-4 inhibition into responders is an active area of investigation. Potential candidates include other immunotherapies, standard chemotherapy, targeted agents [13-15], and radiotherapy has earned a prominent place, due to substantial pre-clinical data [16-20] and rapidly accumulating clinical observations [21-23] that it can induce therapeutically effective anti-tumor immunity when combined with CTLA-4 blockade. Several clinical trials are currently ongoing to test radiotherapy in combination with the FDA-approved anti-CTLA-4 antibody ipilimumab (Yervoy®, Bristol Meyers-Squibb, New York, New York) (Table 1).

Here we review the available data that has informed the rationale for exploiting the synergy of radiation and CTLA-4 blockade.

\section{Radiation-induced in situ tumor vaccination.}

Over the past decade, an improved understanding of the effects of local radiation on tumor-host interactions has led to the recognition that radiotherapy may have a novel role as an inducer of acute inflammation and immunogenic cell death, capable to convert a tumor into an in situ vaccine [24-26]. Pioneering work implicating $\mathrm{T}$ cells in determining the response to radiation was published several decades ago [27]. More recently, the demonstration that $\mathrm{T}$ cells mediate the abscopal effect (out-of-field responses) of radiation in a pre-clinical tumor model [28] has provided a putative mechanism for the intriguing clinical observation that rare patients with disseminated cancer experienced systemic tumor regression after irradiation of a single tumor site [29-32]. 


\subsection{Radiation induces an immunogenic death of cancer cells and priming of tumor- specific T cells.}

Multiple mechanisms that contribute to radiation-induced anti-tumor immunity are emerging and the signals generated by irradiated dying tumor cells are being elucidated.

Priming of anti-tumor immune responses by cytotoxic treatments has been shown to require the presence of an immunogenic cell death (ICD) [33]. ICD relies on the orchestration of specific molecular signals that stimulate cross-presentation of tumor cell antigens by dendritic cells (DCs) to T cells [34]. Mediated by endoplasmic reticulum (ER) stress and autophagy, ICD is characterized by cell surface translocation of calreticulin (CRT), and extracellular release of high-mobility group protein B1 (HMGB1) and ATP [35-37]. CRT is an ER-associated chaperone protein that when expressed on the surface of dying cells promotes their phagocytosis acting as an "eat-me" signal for DCs [38]. HMGB1 is a nuclear protein found in almost all mammalian cells and is secreted by a variety of immune cells to induce pro-inflammatory effects when bound to pattern-recognition receptors (PRRs) such as the toll-like receptor-4 (TLR4) [39]. During cell death extracellular release of HMGB1 delivers both chemotactic and maturation signals to DCs, promoting phagocytosis of dying tumor cell and DC migration to lymph nodes (LN) to cross-present antigens and prime T cells [40, 41]. ATP released from dying cells binds to P2X7 purigenic receptor on DCs and activates the inflammasome, leading to secretion of interleukin (IL)-1 $\beta$ [37]. While in vivo the relative contribution of each of these factors to priming of anti-tumor $\mathrm{T}$ cells remains undefined, radiation has been shown in vitro to generate all three ICD molecular signals [42-44]. 
Recently, additional mechanisms that play a critical role in radiation-induced anti-tumor $\mathrm{T}$ cell priming have been described. Gupta et al., showed that a single $10 \mathrm{~Gy}$ radiation dose induced the activation of intratumoral DCs, measured as up-regulation of co-stimulatory molecules CD86 and CD70 [45]. Activation of intratumoral DCs was shown by Burnette et al. to first require their production of type I interferon (IFN-I) and to be critical for radiation-induced $\mathrm{T}$ cell crosspriming [46]. Moreover, Deng et al. demonstrated that tumor-derived DNA induced IFN-I production by DCs via the stimulator of IFN genes (STING) pathway [47].

It is important to notice that the experimental settings demonstrating priming of $\mathrm{T}$ cells by radiation consist of relatively immunogenic mouse tumors and/or used strong model antigens such as ovalbumin (OVA) as reporter antigens $[48,49]$. In the setting of poorly immunogenic murine tumors, that better model the clinical reality of cancer, radiation by itself is generally insufficient to prime T cell responses [50, 51].

One explanation for the suboptimal vaccination induced by radiation it the possible concomitant activation of immunosuppressive signals. Our recent data support this hypothesis. In two poorly immunogenic murine carcinomas blockade of $\mathrm{TGF} \beta$, which is activated from its latent form by reactive oxygen species (ROS) generated by radiation [52], was required for priming of CD8 T cells specific for three endogenous antigens: The anti-apoptotic protein survivin, the transcription factor twist-1 and, the gp70 envelope glycoprotein of an endogenous retrovirus [53].

Another mechanism of radiation-induced immunosuppression is mediated by the conversion of ATP by CD39 and CD73 into adenosine, which suppresses anti-tumor T cell activation, survival and effector function via the A2a adenosine receptor (A2AR). Adenosine also negatively modulates differentiation and function of DCs and natural killer (NK) cells [54, 55]. Thus, at 
least in some tumors adenosinergic pathways may limit the ability of radiation to induce effective anti-tumor immunity.

Other mechanisms that have been suggested to hamper radiation-induced immunization are a relative increase in regulatory $\mathrm{T}$ cells (Tregs) and in immunosuppressive myeloid cells postradiation $[56,57]$.

Information about the breath and specificity of the anti-tumor $\mathrm{T}$ cell responses primed by radiation is very limited. The antigenic repertoire of a given tumor classically includes selfantigens, like overexpressed differentiation antigens and Cancer-Testis (CT) antigens [58]. Although $\mathrm{T}$ cells can recognize them, some degree of $\mathrm{T}$ cell tolerance usually exists as the result of elimination of $\mathrm{T}$ cells with high affinity $\mathrm{T}$ cell receptor (TCR) during $\mathrm{T}$ cell ontogeny. In experimental models, radiation fails to induce $\mathrm{T}$ cell responses to these relatively weak antigens [53]. However, increase in $\mathrm{T}$ cell responses to self-antigens such as survivin could be detected in occasional patients undergoing radiotherapy [51]. Interestingly, it has been shown that radiation induces the expression of novel epitopes derived from protein that are transcribed in response to radiation-induced damage of cancer cells [59]. Nevertheless it is unclear whether T cells specific for radiation-induced antigens are elicited that contribute to the rejection of the irradiated tumor. Finally, a class of tumor antigens that can elicit strong $\mathrm{T}$ cell responses are mutated neo-antigens [60]. Recent evidence suggests that such mutated neo-antigens are the targets of $\mathrm{T}$ cells during successful tumor rejection and our group is actively investigating whether radiation can induce such responses. 


\subsection{Radiation promotes a pro-immunogenic tumor microenvironment.}

In addition to the signals released by dying cells after exposure to ionizing radiation, signals released by tumor and stromal cells that survive radiation damage modulate the tumor microenvironment $[61,62]$. Effects of radiation that facilitate the effector phase of anti-tumor immune responses include upregulation of specific chemokines and cell surface receptors, as well as vascular changes.

Cancer cells are the source of some of the chemokines induced by radiation. For example, in vitro, mouse and human breast cancer cells, and mouse prostate, colon carcinoma and fibrosarcoma cells increased levels of CXC chemokine ligand (CXCL) 16 upon radiation exposure to doses in the range of 2 to 12 Gy $[19,63]$. In vivo, CXCL16 was critical for efficient recruitment of effector CD8 T cells to irradiated mouse 4T1 breast tumors [19]. In the B16-OVA mouse melanoma model, after radiation the cancer cells produced CXCL9 and CXCL10 in response to IFN- $\gamma$ produced by infiltrating hematopoietic cells [64].

Radiation has also been shown to promote normalization of aberrant vasculature and activation of endothelial cells with upregulation of vascular adhesion molecules, leading to improved tumor infiltration by $\mathrm{T}$ cells $[48,65]$. Interestingly, in a mouse model of pancreatic cancer vascular normalization was achieved with a single 2 Gy dose of radiation, improving tumor rejection by adoptively transferred T cells [65].

Finally, a number of phenotypic changes defined by some investigators as "immunogenic modulation" have been described to occur in neoplastic cells surviving radiation exposure [62]. For instance, post-radiation upregulation of Major Histocompatibility Complex (MHC) class I 
molecules and Fas death receptor on tumor cells promoted tumor rejection by CD8+ T cells in vivo [59, 66, 67]. Moreover, RT induces expression of natural-killer group 2, member D (NKG2D)-ligands, powerful stimulators of both NK and CD8+ T cells [68].

\subsection{Role of radiation dose and fractionation.}

Many of the pro-immunogenic effects of radiation on the cancer cells described above can be induced, at least in vitro, by radiation doses varying from about 2 Gy to as much as 30 Gy or more, but the optimal radiation regimen to induce clinical anti-tumor immunity remains to be defined. Only a few studies have compared different radiation doses and fractionation, or conducted the same experiments in tumor cells with different intrinsic radiosensitivity, [69]. In vitro, a dose-dependent increase of the ICD signals and of some chemokines and surface molecules were reported $[19,43,59]$. In vivo, the nature of the pre-existing tumor microenvironment at the time of radiation and the response of normal stromal cells present within the field of radiation are important determinants of the development of effective antitumor immunity. For instance, Klug et al overcame the immunosuppressive effect of hypoxia by a low dose single dose radiation (2 -5 Gy) that resulted in re-programming of tumor-infiltrating macrophages [65]. On the other hand, priming of OVA-specific T cells was shown to be more pronounced when B16-OVA tumors were irradiated with 15 Gy given as single dose rather than as 5 fractions of 3 Gy each [48]. In another study using the same tumor model, Schaue et al. reported that while a single dose of 15 Gy primed OVA-specific T cells, it also led to a relative increase in Tregs, and showed that the best ratio of anti-tumor $\mathrm{T}$ cells to Tregs was achieved when radiation was given in two fractions of 7.5 Gy [70]. These examples highlight the complex interaction between the irradiated tumor and the host immune system, and suggest that studies to 
optimize the radiation regimen need to take into consideration multiple parameters, likely to also be tumor-type specific. Moreover, combinations of radiation with different immunotherapy strategies may require specific dose regimens and fractionation.

Finally, while radiation can convert the tumor into an in situ vaccine, its effects on the tumor microenvironment persist and evolve long after the time of radiation exposure. The degree and duration of these effects may depend on the degree of pre-existing immunosuppression and the balance between signals that promote tumor rejection versus signals that hinder it. In most cases, radiation therapy alone is unable to induce effective immune-mediated tumor rejection: however it may potentiate immunotherapy, as exemplified by preclinical and clinical work with immune checkpoint blocking agents. We will discuss below the combination of radiation with antiCTLA-4 antibodies.

\section{Cytotoxic T lymphocyte antigen-4, a negative regulator of T-cell activation.}

An array of co-stimulatory and co-inhibitory molecules regulates $\mathrm{T}$ cells activation, balancing the need to eliminate pathogens with the prevention of autoimmunity [71]. T cell activation requires two signals, the first is delivered by TCR binding to MHC-I/antigen. The second is delivered by CD28 costimulatory receptor that binds to CD80 (B7-1) and CD86 (B7-2) on the surface of antigen presenting cells (APC), resulting in abundant secretion of IL-2 and T-cell proliferation [72].

After TCR engagement CTLA-4 is rapidly recruited to the immune synapse where it competes with CD28 for binding to CD80 and CD86. Because of its greater affinity, when co-stimulation 
is suboptimal interactions between CTLA-4 and costimulatory molecules prevail, thus impeding $\mathrm{T}$ cell proliferation [73]. Importantly, CTLA-4 not only hinders the interaction between CD28 and CD80/86 but also impairs $\mathrm{T}$ cell activation by dephosphorylating key effector molecules required for TCR signaling [74, 75]. Additionally, when constitutively expressed on Tregs, CTLA-4 has been shown to reduce expression of CD80 and CD86 on APCs as well as to increase the secretion of TGF $\beta$, thus fostering T cell tolerance to tumors by multiple mechanisms $[76,77]$.

\subsection{Effects of anti-CTLA-4 antibodies on priming of anti-tumor T cells.}

The role of CTLA-4 in limiting the development of anti-tumor immune responses in cancer patients has been demonstrated by the therapeutic success of anti-CTLA-4 monoclonal antibody $(\mathrm{mAb})$ in metastatic melanoma [9]. The mechanisms by which anti-CTLA-4 mAbs unleash antitumor immunity remain incompletely understood. Preclinical studies have shown that CTLA-4 blockade enhances anti-tumor immunity by reducing the threshold for $\mathrm{T}$ cell activation [78], resulting in monoclonal and oligoclonal expansion of $\mathrm{CD} 4 \mathrm{~T}$ cells responding to cognate peptide antigens or super-antigens [79]. Importantly, work by Jim Allison's lab demonstrated that CTLA-4 plays a major role in shaping the breadth of reactivity of a primed T cell population, by constraining the "best-fit" population [80]. Thus, when CTLA-4 is blocked, the lower threshold required for $\mathrm{T}$ cell activation allows proliferation and expansion of tumor antigen-specific $\mathrm{T}$ cells, leading to tumor rejection. Importantly, Kvistborg et al. have recently provided evidence for a similar broadening of melanoma-reactive $\mathrm{T}$ cell responses in patients treated with antiCTLA-4 [81]. 


\subsection{Effects of anti-CTLA-4 antibodies on the effector phase of tumor rejection.}

The ability of anti-CTLA- $4 \mathrm{mAb}$ to promote anti-tumor immunity is not only confined to the priming phase. A common feature associated with anti-CTLA-4 mediated tumor rejection is an increase in the ratio of effector $\mathrm{T}$ to Tregs cells within the tumor $[82,83]$. While effector $\mathrm{T}$ cells are increased due to the pro-proliferative effect of CTLA-4 blockade, recent preclinical data demonstrated that depletion of intratumoral Tregs also plays a major role in tumor rejection. Anti-CTLA-4 mAbs capable of mediating antibody-dependent cellular cytotoxicity (ADCC) effectively and selectively eliminated intratumoral Tregs, which express higher levels of CTLA4 compared to circulating Tregs [84-86]. CTLA-4 ligation on effector T cells has also been shown to enhance motility of both CD4 and CD8 T cells [20, 87, 88]. Using CD8 T cells expressing a Pmel-1 transgenic TCR specific for a melanoma antigen Pentcheva-Hoang et al. showed that increased motility was associated with tumor rejection, and hypothesized that antiCTLA-4 may act by reversing motility paralysis of exhausted intratumoral T cells [87].

\section{Synergy of radiotherapy with anti-CTLA-4 antibody.}

Previous work in pre-clinical models of melanoma and breast cancer showed that tumors insensitive to anti-CTLA-4 treatment as monotherapy became responsive upon vaccination with modified autologous tumor cells $[89,90]$. We hypothesized that in situ vaccination by radiation could also convert a poorly immunogenic tumor, unresponsive to anti-CTLA-4 into a responder. This hypothesis was confirmed in three different murine tumor models, 4T1 and TSA mammary carcinomas syngeneic to BALB/c mice and MCA38 colorectal carcinoma syngeneic to C57BL/6 
mice $[16,17]$. Importantly, the anti-tumor $\mathrm{T}$ cells elicited by the combination not only did reject the irradiated tumor but also inhibited spontaneous 4T1 lung metastases or synchronous unirradiated tumors (abscopal effect) in mice bearing TSA and MCA38 carcinomas [16, 17].

The mechanisms of synergy between radiation and anti-CTLA-4 mAb were studied in more details in the 4T1 model. These studies showed that anti-CTLA-4 therapy and radiation interact at multiple levels, each contributing to tumor rejection (Figure 1). First, development of CD8 T cell responses to the tumor was required for tumor rejection $[16,18]$. Priming of CD8 T cells was monitored in tumor-draining lymph nodes by measuring IFN $\gamma$ production to the $\mathrm{AH} 1 \mathrm{gp} 70$ derived CD8 T cell epitope. Radiation and anti-CTLA-4 antibody induced measurable $\mathrm{T}$ cell priming only when used in combination, indicating that each treatment provided critical non redundant signals. The number of DCs available locally to cross-present the antigens released by radiation determined the magnitude of the elicited anti-tumor $\mathrm{T}$ cell responses [91]. We found that in 4T1 tumor-bearing mice the number of DCs present within the tumor and draining lymph nodes was regulated by invariant natural killer T (iNKT) cells. Blocking CD1d-mediated interaction of iNKT cells with DCs led to an increase in DCs and improved CD8 T cell priming and overall tumor response to the combination of radiation therapy and anti-CTLA-4 treatment [91].

In addition, radiation-induced molecular signals were required for tumor rejection. For instance, CXCL16 upregulation by radiation was required for effector CD8 $\mathrm{T}$ cell homing to $4 \mathrm{~T} 1$ tumors. CXC chemokine receptor (CXCR) 6-deficient mice, whose T-cells are unable to respond to this chemokine, failed to show increased CD8 $\mathrm{T}$ cells infiltration post-treatment and response to radiation and anti-CTLA-4 [19]. 
Finally, intravital imaging using two photon laser scanning microscopy was used to study in vivo how radiation affected the interaction of CD8 $\mathrm{T}$ cells with $4 \mathrm{~T} 1$ cancer cells. To track the polyclonal population of CD8 T cells activated by treatment with radiation and anti-CTLA-4 we used $\mathrm{CXCR6}^{+/ g f p}$ mice. In these mice, GFP expression within the tumor was largely confined to activated tumor-specific CD8 T cells, as determined by their expression of activation markers, ex vivo IFN $\gamma$ production and by the fact that blocking MHC-I disrupted the interaction of $\mathrm{GFP}^{+} \mathrm{T}$ cells with $\mathrm{CFP}^{+} 4 \mathrm{~T} 1$ cells [20]. Some activated CD8 T cells were present in all tumors, although over time they only increased in tumors of mice treated with radiation and anti-CTLA-4. Motility of these T cells was mildly enhanced in irradiated tumors and markedly enhanced in tumor of mice treated with anti-CTLA-4 monotherapy. In contrast, when these two treatments were combined, activated CD8 T cells displayed reduced motility, forming stable contacts with 4T1 cells. Interactions between NKG2D receptor and its ligand retinoic acid early inducible-1 (RAE1), which was induced by radiation on $4 \mathrm{~T} 1$ cells, were required to achieve the stable contacts between tumor and CD8 $\mathrm{T}$ cells. Blocking NKG2D with an antibody increased CD8 T cell speed and abrogated the tumor inhibition achieved with radiation and anti-CTLA-4 [20]. Thus, in the presence of anti-CTLA-4 antibody radiation is providing a signal to promote the formation of an effector immune synapse between CD8 $\mathrm{T}$ and tumor cells. The requirement for coengagement of TCR and NKG2D to achieve a stop signal when CTLA-4 is ligated was supported by additional in vitro data [20]. Intriguingly, while a similar motility enhancement by anti-CTLA-4 treatment was recently reported in intratumoral CD8 T cells expressing a transgenic TCR specific for a melanoma antigen, in the latter experimental system enhanced motility resulted in more effective tumor rejection [87]. This difference may reflect the different requirements for formation of an effector immune synapse for a homogeneous $\mathrm{T}$ cell population 
expressing a TCR with relatively high affinity for an abundant tumor antigen. In our experimental system we studied a polyclonal $\mathrm{T}$ cell population with TCRs of varying affinity for antigens that may be expressed at very low levels within the tumor. Low affinity/avidity TCR interactions with tumor cells will be dependent on NKG2D co-engagement and killing may require a more protracted interaction [92].

Overall, this data supports the multiplicity of effects of radiotherapy on the efficacy of immunotherapy targeting the checkpoint receptor CTLA-4. It is likely that dominant mechanism(s) of interaction between these two modalities mainly depend on the pre-existing tumor microenvironment and host general immune status.

However the type of radiation regimen used may also be a determinant of success. In a comparison of two fractionated radiation regimens (8 Gy X 3 and 6 Gy X 5) and a single large dose (20 Gy) in two tumor models, TSA and MCA38, we found that effective anti-tumor immunity leading to rejection of the irradiated and non-irradiated synchronous tumors (abscopal effect) was only achieved by the fractionated regimens, while the single 20 Gy dose failed to show synergy with anti-CTLA-4 [17]. While the reasons for this difference are being actively investigated, it is intriguing that the two most notable cases of abscopal responses seen in patients with melanoma and lung cancer treated with radiotherapy and ipilimumab occurred with the use of similar fractionated radiotherapy regimens, 9.5 Gy X 3 in the melanoma case, and as 6 Gy X 5 in the lung cancer case $[21,23]$. 


\section{Clinical translation}

Since 2011, after the approval of ipilimumab for patients with metastatic or unresectable melanoma, a few dramatic abscopal responses have been reported after radiation of one metastasis in patients who were unresponsive or had ceased to respond to ipilimumab [21, 22, 93]. These reports have sparked several retrospective analyses of outcome in melanoma patients receiving radiation while treated with ipilimumab, with an excellent review of these studies recently published by Barker and Postow [94]. Most of the patients in these retrospective series received radiation to the brain, and in most cases the analysis suggested a survival benefit associated with the combination. A retrospective study in a cohort of 21 patients who received radiation to the brain or extracranial sites after progression on ipilimumab reported abscopal responses in $62 \%$, which were associated with increased survival [95]. While these cases seem to confirm the preclinical synergy of radiation with ipilimumab, a caveat is the fact that since melanoma is known to respond to ipilimumab the findings could represent late responses attributable to ipilimumab alone. Several prospective trials are ongoing to determine the benefits of the combination of radiation with anti-CTLA-4 antibodies in melanoma (Table 1).

Results of a phase I study in 22 melanoma patients with escalation of the radiation dose were recently reported and confirmed that radiation did not worsen the toxicity expected with ipilimumab alone. There were no complete responses and overall disease control rate was not much higher than what would be expected with ipilimumab alone in melanoma [96]. While this study does not provide conclusive evidence about the benefits of radiation combined with ipilimumab it raises the question of whether two doses of either 6 or $8 \mathrm{~Gy}$, which were received in 12 out of 22 patients, may be suboptimal in melanoma to achieve in situ vaccination. 
A large randomized trial in metastatic castrate-resistant and docetaxel-refractory prostate cancer compared radiation given as a single 8 Gy dose to a bone metastasis with radiation plus ipilimumab. Overall, there was no significant difference in survival between the two arms, but a benefit in the combination arm was seen among patients with good prognostic features [97]. This data suggests that the degree of immune competence may influence the likelihood of response, and again raises the question whether a single 8 Gy dose, may explain the limited success of this study [17]. We have reported a complete abscopal response in a patient with non small cell lung cancer treated with radiation given in 5 fractions of 6 Gy each and ipilimumab [23]. Since lung cancer has been shown to be insensitive to anti-CTLA-4 monotherapy [98] this case supports the hypothesis that radiation could be used to sensitize unresponsive tumor types to anti-CTLA-4 treatment. This hypothesis is currently being tested in a clinical trial (NCT02221739).

\section{Conclusions}

The ability of radiation to elicit anti-tumor immune responses has been unequivocally demonstrated in experimental models, and many of the mechanisms involved have been identified. However, more work is required to define the dose(s) and fractionation that optimally induce anti-tumor $\mathrm{T}$ cells, and identify the tumor characteristics that predict which tumors will respond to a given combination of radiation and immune checkpoint blockade. While the growing number of reports of occasional abscopal responses in patients receiving radiation therapy and anti-CTLA- 4 antibody has generated a lot of interest, the results of the first two completed prospective trials testing radiation and anti-CTLA-4 highlight the need to carefully design future studies. Recent data have emphasized the importance of $\mathrm{T}$ cell responses to unique 
individual tumor antigens [60]. In this context, local radiation deserves to be thoroughly explored for its potential to offer an attractive, easy to use and cost-effective intervention for personalized tumor vaccination.

\section{Acknowledgements}

The authors are grateful to Sophia Ceder (www.ceder.graphics) for illustrating figure 1. SD is supported by grants from the USA Department of Defense Breast Cancer Research Program (W81XWH-11-1-0532), The Chemotherapy Foundation, Breast Cancer Alliance, and Breast Cancer Research Foundation. CV-B is supported by a Post-doctoral fellowship from the Department of Defense Breast Cancer Research Program (W81XWH-13-1-0012). SCF is supported by grants from USA Department of Defense Breast Cancer Research Program (W81XWH-11-1-0530), NIH (R01 CA161891), and Breast Cancer Research Foundation. NYU Perlmutter Cancer Center is supported by NIH 5P30CA016087. 


\section{$\underline{\text { References }}$}

[1] Mittal D, Gubin MM, Schreiber RD, Smyth MJ. New insights into cancer immunoediting and its three component phases-elimination, equilibrium and escape. Curr Opin Immunol. 2014;27C:16-25.

[2] Vesely MD, Kershaw MH, Schreiber RD, Smyth MJ. Natural innate and adaptive immunity to cancer. Annu Rev Immunol. 2011;29:235-71.

[3] Galon J, Costes A, Sanchez-Cabo F, Kirilovsky A, Mlecnik B, Lagorce-Pages C, et al. Type, density, and location of immune cells within human colorectal tumors predict clinical outcome. Science. 2006;313:1960-4.

[4] Pagès F, Galon J, Dieu-Nosjean MC, Tartour E, Sautès-Fridman C, Fridman WH. Immune infiltration in human tumors: a prognostic factor that should not be ignored. Oncogene. 2010;29:1093-102.

[5] Wang E, Miller LD, Ohnmacht GA, Mocellin S, Perez-Diez A, Petersen D, et al. Prospective molecular profiling of melanoma metastases suggests classifiers of immune responsiveness. Cancer Res. 2002;62:3581-6.

[6] Pardoll DM. The blockade of immune checkpoints in cancer immunotherapy. Nat Rev Cancer. 2012;12:252-64.

[7] Gajewski TF, Schreiber H, Fu YX. Innate and adaptive immune cells in the tumor microenvironment. Nat Immunol. 2013;14:1014-22.

[8] Topalian SL, Hodi FS, Brahmer JR, Gettinger SN, Smith DC, McDermott DF, et al. Safety, activity, and immune correlates of anti-PD-1 antibody in cancer. N Engl J Med. 2012;366:244354. 
[9] Hodi FS, O'Day SJ, McDermott DF, Weber RW, Sosman JA, Haanen JB, et al. Improved survival with ipilimumab in patients with metastatic melanoma. N Engl J Med. 2010;363:711-23. [10] Snyder A, Makarov V, Merghoub T, Yuan J, Zaretsky JM, Desrichard A, et al. Genetic basis for clinical response to CTLA-4 blockade in melanoma. N Engl J Med. 2014;371:2189-99. [11] McDermott D, Lebbe C, Hodi FS, Maio M, Weber JS, Wolchok JD, et al. Durable benefit and the potential for long-term survival with immunotherapy in advanced melanoma. Cancer Treat Rev. 2014;40:1056-64.

[12] Postow MA, Callahan MK, Wolchok JD. The antitumor immunity of ipilimumab: (T-cell) memories to last a lifetime? Clin Cancer Res. 2012;18:1821-3.

[13] Lynch TJ, Bondarenko I, Luft A, Serwatowski P, Barlesi F, Chacko R, et al. Ipilimumab in combination with paclitaxel and carboplatin as first-line treatment in stage IIIB/IV non-smallcell lung cancer: results from a randomized, double-blind, multicenter phase II study. J Clin Oncol 2012;30:2046-54.

[14] Wolchok JD, Kluger H, Callahan MK, Postow MA, Rizvi NA, Lesokhin AM, et al. Nivolumab plus Ipilimumab in Advanced Melanoma. N Engl J Med. 2013;369:122-33. [15] Hu-Lieskovan S, Robert L, Homet Moreno B, Ribas A. Combining targeted therapy with immunotherapy in BRAF-mutant melanoma: promise and challenges. J Clin Oncol. 2014;32:2248-54.

[16] Demaria S, Kawashima N, Yang AM, Devitt ML, Babb JS, Allison JP, et al. Immunemediated inhibition of metastases after treatment with local radiation and CTLA-4 blockade in a mouse model of breast cancer. Clin Cancer res. 2005;11:728-34. 
[17] Dewan MZ, Galloway AE, Kawashima N, Dewyngaert JK, Babb JS, Formenti SC, et al. Fractionated but not single dose radiotherapy induces an immune-mediated abscopal effect when combined with anti-CTLA-4 antibody. Clin Cancer Res. 2009;15:5379-88.

[18] Pilones KA, Kawashima N, Yang AM, Babb JS, Formenti SC, Demaria S. Invariant natural killer T cells regulate breast cancer response to radiation and CTLA-4 blockade. . Clin Cancer Res. 2009;15:597-606.

[19] Matsumura S, Wang B, Kawashima N, Braunstein S, Badura M, Cameron TO, et al. Radiation-induced CXCL16 release by breast cancer cells attracts effector T cells. J Immunol. 2008;181:3099-107.

[20] Ruocco MG, Pilones KA, Kawashima N, Cammer M, Huang J, Babb JS, et al. Suppressing T cell motility induced by anti-CTLA-4 monotherapy improves anti-tumor effects. J Clin Invest. 2012;122:3718-30.

[21] Postow MA, Callahan MK, Barker CA, Yamada Y, Yuan J, Kitano S, et al. Immunologic correlates of the abscopal effect in a patient with melanoma. N Engl J Med. 2012;366:925-31. [22] Hiniker SM, Chen DS, Reddy S, Chang DT, Jones JC, Mollick JA, et al. A systemic complete response of metastatic melanoma to local radiation and immunotherapy. Transl Oncol. 2012;5:404-7.

[23] Golden EB, Demaria S, Schiff PB, Chachoua A, Formenti SC. An abscopal response to radiation and ipilimumab in a patient with metastatic non-small cell lung cancer. Cancer Immunol Res. 2013;1:365-72.

[24] Demaria S, Bhardwaj N, McBride WH, Formenti SC. Combining radiotherapy and immunotherapy: a revived partnership. Int J Radiat Oncol Biol Phys. 2005;63:655-66. 
[25] Formenti SC, Demaria S. Radiotherapy to convert the tumor into an in situ vaccine. Int J Radiat Oncol Biol Phys. 2012;84:879-80.

[26] Ma Y, Kepp O, Ghiringhelli F, Apetoh L, Aymeric L, Locher C, et al. Chemotherapy and radiotherapy: cryptic anticancer vaccines. Semin Immunol. 2010;22:113-24.

[27] Stone HB, Peters LJ, Milas L. Effect of host immune capability on radiocurability and subsequent transplantability of a murine fibrosarcoma. J Natl Cancer Inst. 1979;63:1229-35. [28] Demaria S, Ng B, Devitt ML, Babb JS, Kawashima N, Liebes L, et al. Ionizing radiation inhibition of distant untreated tumors (abscopal effect) is immune mediated. Int J Radiat Oncol Biol Phys. 2004;58:862-70.

[29] Ehlers G, Fridman M. Abscopal effect of radiation in papillary adenocarcinoma. Br J Radiol. 1973;46:220-2.

[30] Formenti SC, Demaria S. Systemic effects of local radiotherapy. Lancet Oncol. 2009;10:718-26.

[31] Kingsley DP. An interesting case of possible abscopal effect in malignant melanoma. Br J Radiol. 1975;48:863-6.

[32] Rees GJ, Ross CM. Abscopal regression following radiotherapy for adenocarcinoma. Br J Radiol. 1983;56:63-6.

[33] Kroemer G, Galluzzi L, Kepp O, Zitvogel L. Immunogenic cell death in cancer therapy. Annu Rev Immunol. 2013;31:51-72.

[34] Zitvogel L, Kepp O, Kroemer G. Decoding cell death signals in inflammation and immunity. Cell. 2010;140:798-804.

[35] Obeid M, Tesniere A, Ghiringhelli F, Fimia GM, Apetoh L, Perfettini JL, et al. Calreticulin exposure dictates the immunogenicity of cancer cell death. Nat Med. 2007;13:54-61. 
[36] Apetoh L, Ghiringhelli F, Tesniere A, Obeid M, Ortiz C, Criollo A, et al. Toll-like receptor 4-dependent contribution of the immune system to anticancer chemotherapy and radiotherapy. Nat Med. 2007;13:1050-9.

[37] Ghiringhelli F, Apetoh L, Tesniere A, Aymeric L, Ma Y, Ortiz C, et al. Activation of the NLRP3 inflammasome in dendritic cells induces IL-1beta-dependent adaptive immunity against tumors. Nat Med. 2009;15:1170-8.

[38] Gardai SJ, McPhillips KA, Frasch SC, Janssen WJ, Starefeldt A, Murphy-Ullrich JE, et al. Cell-surface calreticulin initiates clearance of viable or apoptotic cells through trans-activation of LRP on the phagocyte. Cell. 2005;123:321-34.

[39] Scaffidi P, Misteli T, Bianchi ME. Release of chromatin protein HMGB1 by necrotic cells triggers inflammation. Nature. 2002;418:191-5.

[40] Dumitriu IE, Baruah P, Valentinis B, Voll RE, Herrmann M, Nawroth PP, et al. Release of high mobility group box 1 by dendritic cells controls $\mathrm{T}$ cell activation via the receptor for advanced glycation end products. J Immunol. 2005;174:7506-15.

[41] Moser B, Desai DD, Downie MP, Chen Y, Yan SF, Herold K, et al. Receptor for advanced glycation end products expression on $\mathrm{T}$ cells contributes to antigen-specific cellular expansion in vivo. J Immunol. 2007;179:8051-8.

[42] Apetoh L, Ghiringhelli F, Tesniere A, Criollo A, Ortiz C, Lidereau R, et al. The interaction between HMGB1 and TLR4 dictates the outcome of anticancer chemotherapy and radiotherapy. Immunol Rev. 2007;220:47-59.

[43] Golden EB, Derek F, Pellicciotta I, Demaria S, Barcellos-Hoff MH, Formenti SC. Radiation fosters dose-dependent and chemotherapy-induced immunogenic cell death. . OncoImmunology. 2014;25:e28518. 
[44] Obeid M, Panaretakis T, Joza N, Tufi R, Tesniere A, van Endert P, et al. Calreticulin exposure is required for the immunogenicity of gamma-irradiation and UVC light-induced apoptosis. Cell Death Differ. 2007;14:1848-50.

[45] Gupta A, Probst HC, Vuong V, Landshammer A, Muth S, Yagita H, et al. Radiotherapy promotes tumor-specific effector CD8+ T cells via dendritic cell activation. J Immunol. 2012;189:558-66.

[46] Burnette BC, Liang H, Lee Y, Chlewicki L, Khodarev NN, Weichselbaum RR, et al. The efficacy of radiotherapy relies upon induction of type i interferon-dependent innate and adaptive immunity. Cancer Res. 2011;71:2488-96.

[47] Deng L, Liang H, Xu M, Yang X, Burnette B, Arina A, et al. STING-Dependent Cytosolic DNA Sensing Promotes Radiation-Induced Type I Interferon-Dependent Antitumor Immunity in Immunogenic Tumors. Immunity. 2014;41:843-52.

[48] Lugade AA, Moran JP, Gerber SA, Rose RC, Frelinger JG, Lord EM. Local radiation therapy of B16 melanoma tumors increases the generation of tumor antigen-specific effector cells that traffic to the tumor. J Immunol. 2005;174:7516-23.

[49] Lee Y, Auh SL, Wang Y, Burnette B, Wang Y, Meng Y, et al. Therapeutic effects of ablative radiation on local tumor require CD8+ T cells: changing strategies for cancer treatment. Blood. 2009;114:589-95.

[50] Demaria S, Kawashima N, Yang AM, Devitt M-L, Babb JS, Allison JP, et al. Immunemediated inhibition of metastases following treatment with local radiation and CTLA-4 blockade in a mouse model of breast cancer. Clin Cancer Res. 2005;11:728-34. 
[51] Schaue D, Comin-Anduix B, Ribas A, Zhang L, Goodglick L, Sayre JW, et al. T-cell responses to survivin in cancer patients undergoing radiation therapy. Clin Cancer Res. 2008;14:4883-90.

[52] Barcellos-Hoff MH, Derynck R, Tsang ML, Weatherbee JA. Transforming growth factorbeta activation in irradiated murine mammary gland. J Clin Invest. 1994;93:892-9.

[53] Vanpouille-Box C, Diamond JM, Pilones KA, Zavadil J, Babb JS, Formenti SC, et al. TGFbeta is a master regulator of radiation therapy-induced anti-tumor immunity. Cancer Res. 2015.

[54] Cekic C, Linden J. Adenosine A2A receptors intrinsically regulate CD8+ T cells in the tumor microenvironment. Cancer Res. 2014;74:7239-49.

[55] Hoskin DW, Mader JS, Furlong SJ, Conrad DM, Blay J. Inhibition of T cell and natural killer cell function by adenosine and its contribution to immune evasion by tumor cells (Review). Int J Oncol. 2008;32:527-35.

[56] Schaue D, Xie MW, Ratikan JA, McBride WH. Regulatory T cells in radiotherapeutic responses. Front Oncol. 2012;2:90.

[57] Tsai CS, Chen FH, Wang CC, Huang HL, Jung SM, Wu CJ, et al. Macrophages from irradiated tumors express higher levels of iNOS, arginase-I and COX-2, and promote tumor growth. Int J Radiat Oncol Biol Phys. 2007;68:499-507.

[58] Vigneron, ., Stroobant V, Van den Eynde BJ, van der Bruggen P. Database of T cell-defined human tumor antigens: the 2013 update. Cancer Immun. 2013;13:15.

[59] Reits EA, Hodge JW, Herberts CA, Groothuis TA, Chakraborty M, Wansley EK, et al. Radiation modulates the peptide repertoire, enhances MHC class I expression, and induces successful antitumor immunotherapy. J Exp Med. 2006;203:1259-71. 
[60] Schumacher TN, Schreiber RD. Neoantigens in cancer immunotherapy. Science. 2015;348:69-74.

[61] Demaria S, Formenti SC. Sensors of ionizing radiation effects on the immunological microenvironment of cancer. Int J Radiat Biol. 2007;83:819-25.

[62] Kwilas AR, Donahue RN, Bernstein MB, Hodge JW. In the field: exploiting the untapped potential of immunogenic modulation by radiation in combination with immunotherapy for the treatment of cancer. Front Oncol. 2012;2:104.

[63] Matsumura S, Demaria S. Up-regulation of the pro-inflammatory chemokine CXCL16 is a common response of tumor cells to ionizing radiation. Radiat Res. 2010;173:418-25.

[64] Lugade AA, Sorensen EW, Gerber SA, Moran JP, Frelinger JG, Lord EM. Radiationinduced IFN-gamma production within the tumor microenvironment influences antitumor immunity. J Immunol. 2008;180:3132-9.

[65] Klug F, Prakash H, Huber PE, Seibel T, Bender N, Halama N, et al. Low-dose irradiation programs macrophage differentiation to an iNOS $(+) / \mathrm{M} 1$ phenotype that orchestrates effective $\mathrm{T}$ cell immunotherapy. Cancer Cell. 2013;24:589-602.

[66] Garnett CT, Palena C, Chakarborty M, Tsang KY, Schlom J, Hodge JW. Sublethal irradiation of human tumor cells modulates phenotype resulting in enhanced killing by cytotoxic T lymphocytes. Cancer Res. 2004;64:7985-94.

[67] Chakraborty M, Abrams SI, Camphausen K, Liu K, Scott T, Coleman CN, et al. Irradiation of tumor cells up-regulates Fas and enhances CTL lytic activity and CTL adoptive immunotherapy. J Immunol. 2003;170:6338-47. 
[68] Gannage M, Buzyn A, Bogiatzi SI, Lambert M, Soumelis V, Dal Cortivo L, et al. Induction of NKG2D ligands by gamma radiation and tumor necrosis factor-alpha may participate in the tissue damage during acute graft-versus-host disease. Transplantation. 2008;85:911-5.

[69] Demaria S, Formenti SC. Radiation as an immunological adjuvant: current evidence on dose and fractionation. Front Oncol. 2012;2:153.

[70] Schaue D, Ratikan JA, Iwamoto KS, McBride WH. Maximizing tumor immunity with fractionated radiation. Int J Radiat Oncol Biol Phys. 2012;83:1306-10.

[71] Zang X, Allison JP. The B7 family and cancer therapy: costimulation and coinhibition. Clin Cancer Res. 2007;13:5271-9.

[72] Acuto O, Michel F. CD28-mediated co-stimulation: a quantitative support for TCR signalling. Nature reviews Immunology. 2003;3:939-51.

[73] Peggs KS, Quezada SA, Allison JP. Cell intrinsic mechanisms of T-cell inhibition and application to cancer therapy. Immunological reviews. 2008;224:141-65.

[74] Lee KM, Chuang E, Griffin M, Khattri R, Hong DK, Zhang W, et al. Molecular basis of T cell inactivation by CTLA-4. Science. 1998;282:2263-6.

[75] Marengere LE, Waterhouse P, Duncan GS, Mittrucker HW, Feng GS, Mak TW. Regulation of T cell receptor signaling by tyrosine phosphatase SYP association with CTLA-4. Science. 1996;272:1170-3.

[76] Qureshi OS, Zheng Y, Nakamura K, Attridge K, Manzotti C, Schmidt EM, et al. TransEndocytosis of CD80 and CD86: A Molecular Basis for the Cell-Extrinsic Function of CTLA-4. Science. 2011;332:600-3. 
[77] Chen W, Jin W, Wahl SM. Engagement of cytotoxic T lymphocyte-associated antigen 4 (CTLA-4) induces transforming growth factor beta (TGF-beta) production by murine CD4(+) T cells. J Exp Med. 1998;188:1849-57.

[78] Leach D, Krummel M, Allison JP. Enhancement of anti-tumor immunity By CTLA4blockade. Science. 1996;271:1734-6.

[79] Kearney ER, Walunas TL, Karr RW, Morton PA, Loh DY, Bluestone JA, et al. Antigendependent clonal expansion of a trace population of antigen-specific CD4+ T cells in vivo is dependent on CD28 costimulation and inhibited by CTLA-4. J Immunol. 1995;155:1032-6. [80] Kuhns MS, Epshteyn V, Sobel RA, Allison JP. Cytotoxic T lymphocyte antigen-4 (CTLA4) regulates the size, reactivity, and function of a primed pool of CD4+ T cells. Proc Natl Acad Sci U S A. 2000;97:12711-6.

[81] Kvistborg P, Philips D, Kelderman S, Hageman L, Ottensmeier C, Joseph-Pietras D, et al. Anti-CTLA-4 therapy broadens the melanoma-reactive CD8+ T cell response. Sci Trans Med. 2014;6:254ra128.

[82] Quezada SA, Peggs KS, Curran MA, Allison JP. CTLA4 blockade and GM-CSF combination immunotherapy alters the intratumor balance of effector and regulatory $\mathrm{T}$ cells. $\mathrm{J}$ Clin Invest. 2006;116:1935-45.

[83] Liakou CI, Kamat A, Tang DN, Chen H, Sun J, Troncoso P, et al. CTLA-4 blockade increases IFNgamma-producing CD4+ICOShi cells to shift the ratio of effector to regulatory T cells in cancer patients. Proc Natl Acad Sci U S A. 2008;105:39.

[84] Simpson TR, Li F, Montalvo-Ortiz W, Sepulveda MA, Bergerhoff K, Arce F, et al. Fcdependent depletion of tumor-infiltrating regulatory $\mathrm{T}$ cells co-defines the efficacy of antiCTLA-4 therapy against melanoma. J Exp Med. 2013;210:1695-710. 
[85] Bulliard Y, Jolicoeur R, Windman M, Rue SM, Ettenberg S, Knee DA, et al. Activating Fc gamma receptors contribute to the antitumor activities of immunoregulatory receptor-targeting antibodies. J Exp Med. 2013;210:1685-93.

[86] Selby MJ, Engelhardt JJ, Quigley M, Henning KA, Chen T, Srinivasan M, et al. AntiCTLA-4 Antibodies of IgG2a Isotype Enhance Antitumor Activity through Reduction of Intratumoral Regulatory T Cells. Cancer Immunol Res. 2013;OnlineFirst April 7:doi:10.1158/2326-6066.CIR-13-0013

[87] Pentcheva-Hoang T, Simpson TR, Montalvo-Ortiz W, Allison JP. Cytotoxic T Lymphocyte Antigen-4 Blockade Enhances Antitumor Immunity by Stimulating Melanoma-Specific T-cell Motility. Cancer Immunol Res. 2014.

[88] Schneider H, Downey J, Smith A, Zinselmeyer BH, Rush C, Brewer JM, et al. Reversal of the TCR stop signal by CTLA-4. Science. 2006;313:1972-5.

[89] Hurwitz AA, Townsend SE, Yu TF, Wallin JA, Allison JP. Enhancement of the anti-tumor immune response using a combination of interferon-gamma and B7 expression in an experimental mammary carcinoma. Int J Cancer. 1998;77:107-13.

[90] van Elsas A, Hurwitz AA, Allison JP. Combination immunotherapy of B16 melanoma using anti-cytotoxic T-lymphocyte-associated antigen 4 (CTLA-4) and granulocyte/macrophage colony-stimulating factor (GM-CSF)-producing vaccines induces rejection of subcutaneous and metastatic tumors accompanied by autoimmune depigmentation. J Exp Med. 1999;190:355-66. [91] Pilones KA, Aryankalayil J, Babb JS, Demaria S. Invariant natural killer T cells regulate anti-tumor immunity by controlling the population of dendritic cells in tumor and draining lymph nodes. J Immunother Cancer. 2014;2:37. 
[92] Demaria S, Dustin ML. Role of the crosstalk between CTLA-4 and NKG2D in the development of anti-CTLA-4 treatment strategies. Immunotherapy. 2013;5:109-12.

[93] Stamell EF, Wolchok JD, Gnjatic S, Lee NY, Brownell I. The Abscopal Effect Associated With a Systemic Anti-melanoma Immune Response. Int J Radiat Oncol Biol Phys. 2013;85:2935.

[94] Barker CA, Postow MA. Combinations of radiation therapy and immunotherapy for melanoma: a review of clinical outcomes. Int J Radiat Oncol Biol Phys. 2014;88:986-97. [95] Grimaldi AM, Simeone E, Giannarelli D, Muto P, Falivene S, Borzillo V, et al. Abscopal effects of radiotherapy on advanced melanoma patients who progressed after ipilimumab immunotherapy. Oncoimmunology. 2014;3:e28780.

[96] Twyman-Saint Victor C, Rech AJ, Maity A, Rengan R, Pauken KE, Stelekati E, et al. Radiation and dual checkpoint blockade activate non-redundant immune mechanisms in cancer. Nature. 2015;520:373-7.

[97] Kwon ED, Drake CG, Scher HI, Fizazi K, Bossi A, van den Eertwegh AJ, et al. Ipilimumab versus placebo after radiotherapy in patients with metastatic castration-resistant prostate cancer that had progressed after docetaxel chemotherapy (CA184-043): a multicentre, randomised, double-blind, phase 3 trial. Lancet Oncol. 2014;15:700-12.

[98] Zatloukal P, Heo DS, Park K, Kang J, Butts C, Bradford D, et al. Randomized phase II clinical trial comparing tremelimumab (CP-675, 206) with best supportive care (BSC) following first-line platinum-based therapy in patients (pts) with advanced non-small cell lung cancer (NSCLC). J Clin Oncol 2009;27:(suppl; abstr 8071). 
$\underline{\text { Figure Legends }}$

Figure 1: Mechanisms of synergy between radiotherapy and anti-CTLA-4 treatment.

Schematic illustration highlighting the critical changes induced by each treatment in the tumordraining lymph nodes (dLNs) and tumor. Untreated tumors: Priming of T cells in dLN is limited by negative signals delivered by CTLA-4. In the tumor, tumor rejection by CD8 T cells is hampered by low MHC class I and immune-stimulatory ligands (e.g., RAE-1) on tumor cells, and by the immunosuppressive tumor microenvironment, rich in TGF $\beta$, Tregs and tolerogenic DCs. Anti-CTLA-4 treatment: Activation and expansion of tumor-specific $\mathrm{T}$ cells in dLNs is improved by blocking CTLA-4-mediated negative signal, but it remains suboptimal in the setting of poorly immunogenic tumors due to low antigen availability and low activation of DC. Clearance of intratumoral CTLA- $4^{\text {hi }}$ Tregs is mediated by anti-CTLA-4 mAb via ADCC if Fc $\gamma$ Rexpressing myeloid cells are present. At the same time, the pro-motility effects of CTLA-4 ligation hinder the formation of a stable immune synapse between activated CD8 T cells and tumor cells. Radiation: induction of ICD provides tumor antigens and activation signals to DCs, but cross-presentation of tumor-derived antigens to CD8 T cells in dLNs is limited by inhibitory signaling via CTLA-4. Radiation combined with anti-CTLA-4: priming of tumor-specific CD8 T cells is markedly enhanced by complementary effects of radiation and anti-CTLA-4. In addition, activated $\mathrm{T}$ cell homing to the tumor is facilitated by increased levels of chemokines (CXCL16 and CXCL10) released by tumor cells in response to radiation. Inside the tumor, co-engagement of TCR and NKG2D on CD8 T cells by radiation-induced MHC-I and RAE-1 allow formation of 
stable immune synapses with tumor cells. Overall, radiation and anti-CTLA-4 therapy have complementary effects that underlie their synergistic interaction in inducing tumor rejection. 


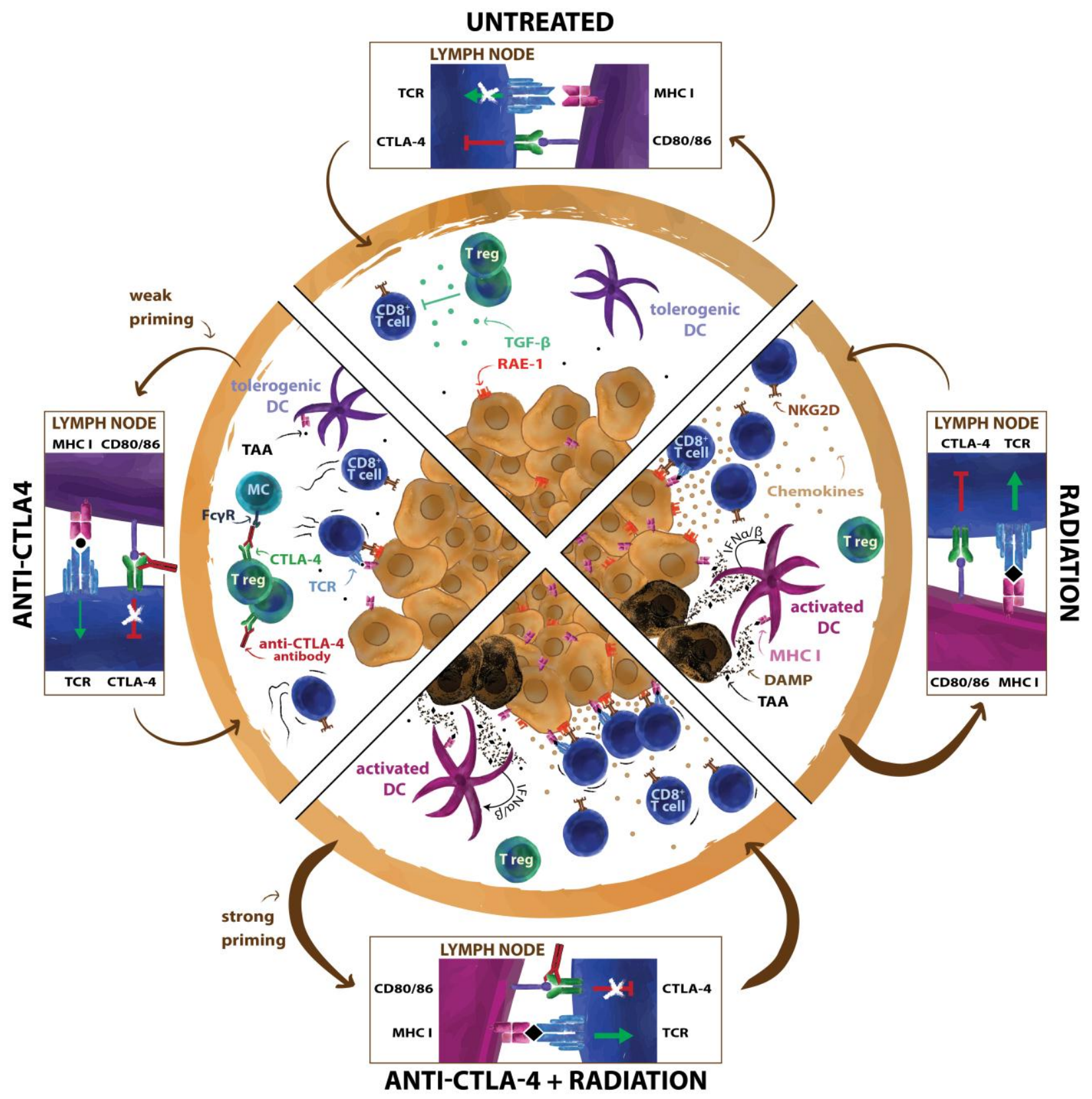


Table 1: Ongoing clinical trials testing the combination of CTLA-4 blockade and radiation therapy (RT).

\begin{tabular}{|c|c|c|c|}
\hline Identifier & Condition & Intervention & Phase \\
\hline NCT01689974 & Metastatic melanoma & $\begin{array}{l}\text { Ipilimumab } \\
\text { Radiation Therapy and Ipilimumab }\end{array}$ & Phase 2 \\
\hline NCT02254772 & $\begin{array}{l}\text { B-cell Lymphomas, multiple } \\
\text { types }\end{array}$ & $\begin{array}{l}\text { Ipilimumab } \\
\text { TLR9 agonist SD-101 } \\
\text { Radiation therapy }\end{array}$ & $\begin{array}{l}\text { Phase } 1 \\
\text { Phase } 2\end{array}$ \\
\hline NCT01703507 & $\begin{array}{l}\text { Recurrent Melanoma } \\
\text { Stage IV Melanoma } \\
\text { Tumors Metastatic to Brain }\end{array}$ & $\begin{array}{l}\text { Ipilimumab } \\
\text { Whole-Brain Radiation Therapy (WBRT) } \\
\text { Stereotactic Radiosurgery (SRS) }\end{array}$ & Phase 1 \\
\hline NCT02239900 & $\begin{array}{l}\text { Liver Cancer } \\
\text { Lung Cancer }\end{array}$ & $\begin{array}{l}\text { Ipilimumab } \\
\text { Stereotactic Body Radiation Therapy (SBRT) }\end{array}$ & $\begin{array}{l}\text { Phase } 1 \\
\text { Phase } 2\end{array}$ \\
\hline NCT01970527 & $\begin{array}{l}\text { Recurrent Melanoma } \\
\text { Stage IV Melanoma }\end{array}$ & $\begin{array}{l}\text { SBRT } \\
\text { Ipilimumab }\end{array}$ & Phase 2 \\
\hline NCT01557114 & Malignant Melanoma & $\begin{array}{l}\text { Ipilimumab } \\
\text { Radiotherapy }\end{array}$ & Phase 1 \\
\hline NCT02221739 & Non-small Cell Lung Cancer & $\begin{array}{l}\text { Ipilimumab } \\
\text { Intensity-modulated radiation therapy (IMRT) }\end{array}$ & Phase 2 \\
\hline NCT01449279 & Melanoma & $\begin{array}{l}\text { Ipilimumab } \\
\text { Radiation Therapy }\end{array}$ & PILOT \\
\hline NCT01565837 & Melanoma & $\begin{array}{l}\text { Ipilimumab } \\
\text { Stereotactic Ablative Radiosurgery (SART) }\end{array}$ & Phase 2 \\
\hline NCT02107755 & $\begin{array}{l}\text { Liver Metastases } \\
\text { Lung Metastases } \\
\text { Recurrent Melanoma } \\
\text { Stage IV Melanoma } \\
\text { Tumors Metastatic to Brain }\end{array}$ & $\begin{array}{l}\text { Iipilimumab } \\
\text { Stereotactic radiosurgery }\end{array}$ & Phase 2 \\
\hline NCT01996202 & High Risk Melanoma & $\begin{array}{l}\text { Ipilumimab } \\
\text { Radiation }\end{array}$ & Phase 1 \\
\hline NCT02097732 & $\begin{array}{l}\text { Metastatic Melanoma } \\
\text { Brain Metastases }\end{array}$ & $\begin{array}{l}\text { Ipilimumab } \\
\text { Stereotactic Radiosurgery (SRS) }\end{array}$ & Phase 2 \\
\hline NCT01950195 & $\begin{array}{l}\text { Newly Diagnosed Melanoma } \\
\text { Metastases in the Brain and } \\
\text { Spine }\end{array}$ & $\begin{array}{l}\text { SRS } \\
\text { Ipilimumab }\end{array}$ & Phase 1 \\
\hline NCT01711515 & Cervical Carcinoma & $\begin{array}{l}\text { Cisplatin } \\
\text { External beam radiation therapy } \\
\text { Brachytherapy } \\
\text { Ipilimumab }\end{array}$ & Phase 1 \\
\hline NCT01935921 & $\begin{array}{l}\text { Stage III and IV Head and } \\
\text { Neck Cancer }\end{array}$ & $\begin{array}{l}\text { Cetuximab } \\
\text { IMRT } \\
\text { Ipilimumab }\end{array}$ & Phase 1 \\
\hline NCT02115139 & $\begin{array}{l}\text { Melanoma } \\
\text { Brain Metastases }\end{array}$ & $\begin{array}{l}\text { Ipilimumab } \\
\text { WBRT }\end{array}$ & Phase 2 \\
\hline NCT01860430 & Head and Neck cancer & Cetuximab/IMRT Plus Ipilimumab & Phase 1 \\
\hline NCT01730157 & $\begin{array}{l}\text { Ocular Melanoma } \\
\text { Extraocular Extension } \\
\text { Melanoma } \\
\text { Metastatic ocular melanoma }\end{array}$ & $\begin{array}{l}\text { Ipilimumab } \\
\text { yttrium Y } 90 \text { glass microspheres }\end{array}$ & Phase 0 \\
\hline NCT02406183 & Metastatic Melanoma & $\begin{array}{l}\text { Ipilimumab } \\
\text { SBRT }\end{array}$ & Phase 1 \\
\hline
\end{tabular}

